\title{
The solid-phase anhydroheterocyclization of 2,2'-dihydroxy-3,3',5,5'-tetra-tert-butylbiphenyl under the action of dioxane dibromide
}

\author{
I. S. Belostotskaya, ${ }^{\star}$ V. B. Vol'eva, N. L. Komissarova, and V. V. Ershov \\ N. M. Emanuel Institute of Biochemical Physics, Russian Academy of Sciences, \\ 4 ul. Kosygina, 117977 Moscow, Russian Federation.
}

Fax: +7 (095) 9382156

We have found that $2,2^{\prime}$-dihydroxy-3,3',5,5'-tetratert-butylbiphenyl (1), when ground with dioxane dibromide (DDB) $(0.2$ to 1 mole of DDB per mole of compound 1), was quantitatively converted into 2,4,6,8-tetra-tert-butyldibenzofuran (2) over a period of several minutes. The compound obtained requires no additional purification, since DDB and the water liberated are spontaneously removed; m.p. $208-209{ }^{\circ} \mathrm{C}$ (from $\mathrm{MeOH}$ ) corresponds to the literature data. ${ }^{1}$

It is noteworthy that the mixture is not liquefied during the reaction. Thus, DDB acts as the catalyst of the solid-phase anhydroheterocyclization of compound 1 , the mechanism of the transformation of 1 into 2 (Scheme 1) being probably similar to the mechanism of the liquid-phase process considered in the previous communication. ${ }^{2}$

We also found that the extreme ease of the transformation observed is a specific property of compound $\mathbf{1}$. Under identical conditions its nonsubstituted analog, 2,2'-dihydroxybiphenyl (3), is brominated with DDB, and no benzofuran is detected among the reaction products. It is natural to assume that the tert-butyl groups in compound $\mathbf{1}$ accomplish the double function of position protectors that protect the rings from halogenation and sterically protect the $\mathrm{OH}$ groups from participating in the formation of intermolecular hydrogen bonds, which would compete with the formation of intramolecular hydrogen bonds.

The reaction of compound 3 with DDB was monitored by TLC on Silufol $U_{254}$ plates. This process was found to yield a mixture of bromo-derivatives of 3 , the corresponding dibenzofuran being completely absent.

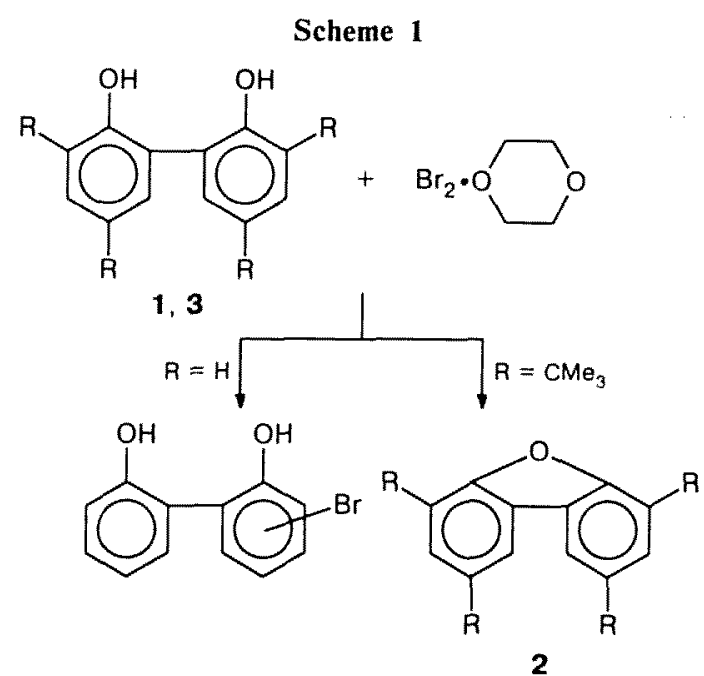

$\mathrm{R}=\mathrm{CMe}_{3}(1), \mathrm{H}(3)$

The work was carried out with financial support of the Russian Foundation for Basic Research (Project No. 94-03-08653).

\section{References}

1. E. Muller, R. Mayer, B. Narr, A. Rieker, and K. Scheffer, Ann. Chem., 1961, 645, 25.

2. V. B. Vol'eva, I. S. Belostotskaya, and V. V. Ershov, Izv. Akad. Nauk, Ser. Khim., 1996, 784 [Russ. Chem. Bull., 1996, 45, 744 (Engl. Transl.)).

Received December 29, 1995

Translated from Izvestiya Akademii Nauk. Seriya Khimicheskaya, No. 4, pp. 1032-1033, April, 1996. 